\title{
ROSARITA FLEURY E AS MULHERES DA ACADEMIA FEMININA DE LETRAS E ARTES DE GOIÁS (AFLAG)
}

\section{ROSARITA FLEURY AND THE WOMEN OF THE FEMALE ACADEMY OF LETTERS AND ARTS OF GOIÁS (AFLAG)}

Débora de Faria Maia ${ }^{1}$

Resumo: No presente trabalho, será analisada a Academia Feminina de Letras e Artes de Goiás (AFLAG). Fundada em 09 de Novembro de 1969, composta unicamente por mulheres, escritoras goianas, artistas plásticas e teatrólogas. Esta academia tem sua importância histórica para as mulheres devido ao objetivo de promover e incentivar a Literatura e as Artes no Estado de Goiás por meio dos trabalhos literários e memória de suas Patronas. A análise fornece uma divulgação sobre produções e atuações literárias de algumas destas, apresentados como material de pesquisa. Busca-se averiguar a vida e trajetória de Maria do Rosário Fleury, fundadora e idealizadora da Academia, e junto a esta, contextualizarmos as demais confreiras, trazendo destaque na atuação política e construtiva das mulheres escritoras em Goiânia- Goiás.

Palavras-chave: Relações de Gênero; Mulheres; Memória; Literatura; Artes.

Abstract: In the following essay, the Feminine Academy of Letters and Arts of Goiás (AFLAG) will be analyzed. Founded on November 9, 1969, it is composed exclusively of women, Goian women writers, plastic artists and theatrical artists. This academy has its historical importance for women due to the objective of promoting and encouraging Literature and the Arts in the State of Goiás through the literary works and memory of its Patrons. This analysis provides a disclosure about the productions and literary performances of some of these patrons, presented as research material. It seeks to research the life and trajectory of Maria do Rosário Fleury, founder and idealizer of the Academy, and with it, contextualize the other confreiras, bringing prominence in the political and constructive action of women writers in Goiânia-Goiás.

Palavras-chave: Gender Relations; Women; Memory; Literature; Art.

\section{INTRODUÇÃO}

Emancipação feminina por meio da escrita: estudos sobre as mulheres e novas fontes.

Estas mulheres promovem uma espécie de emancipação da sua escrita, por meio da literatura, e através dos pequenos projetos de militância intensivas no campo intelectual, tendo a pretensão de enaltecer o pensamento histórico pela produção e atuação feminina. Essa atuação se manifesta crescente através de obras como crônicas, poesias e lírica, que vão ganhando espaço de análise nas linhas de pesquisa da História das Mulheres e Gênero estas hoje utilizadas como fontes nos campos de pesquisa também da História Cultural, das Subjetividades e do uso de outras formas documentais.
Chartier $^{1}$ consente em que haverá a valorização do empirismo histórico para representar e construir sentido na formação historiográfica que forma o campo da História Cultural, na qual muitas destas obras tornam-se hoje fontes para estudo, enaltece assim à importância da categoria "gênero" para a história. Algumas destas publicações aqui mencionadas foram reunidas em instituições fundadas durante o século XX como, por exemplo, a Academia Feminina de Letras e artes de Goiás ou Academia de Letras Goiana (AFLAG), da Cidade de Goiás, antiga Vila Boa, sendo de autoria e idealização unicamente por mulheres.

${ }^{1}$ CHARTIER. O Mundo como vontade e representação. Estudos avançados/1991.

${ }^{1}$ Graduada em História pela Universidade Federal de Goiás, possui ênfase nas pesquisas de Gênero em 2015 e Saúde e Doenças em Goiás 2016/2017, com recorte temporal História de Goiás/Regional. - debora.maia06@hotmail.com 
Eliane Vasconcelos $^{2}$ afirma que, a possibilidade das mulheres de exibirem seu talento para fora das lides puramente domésticas revela-nos uma aura de escritor profundamente interessante, que não só atraia a mulher, sendo de profundo interesse por parte destas, como lhes abria a possibilidades, estas de grande relevância para as pesquisas. A historiadora e pesquisadora nos relata que estas escritoras são mencionadas em trabalhos e dicionários literários apenas recentemente, assim como a fundadora da Academia, e destaque desta pesquisa, Rosarita Fleury, e desta forma podemos compreender o quanto a produção intelectual feminina se manifesta ativa, porém é negligenciada e tratada como irrelevante durante décadas de pesquisa histórica.

Trago aqui um mais um destes exemplos crassos, uma das participantes da Academia Feminina de Letras e Artes de Goiás (AFLAG) da qual se origina esta pesquisa, é Eurídice Natal e Silva. Esta mulher já no inicio do século XX, funda e idealiza a Academia de Letras presente na cidade de Goiás em 1904, inclusive, o autor Gilberto Mendonça Teles fala da importância desta academia que desapareceu em 1908, juntamente com todas as perspectivas de Eurídice em publicar seus contos. Revela-se aqui uma liderança feminina como tal, trazendo consigo a mulher goiana como pioneira na formação do conhecimento exclusivo das mulheres, e um espaço para expô-lo, tendo como nicho de atuação a Cidade de Goiás.

\footnotetext{
${ }^{2}$ Artigo publicado pela Revista UFG, "Percursoras da Literatura Goiana". Julho/2010.
}

Os historiadores que se debruçam na memória e história oral, por exemplo, sabem que as mulheres estão presentes, ávidas por um espaço de fala, e o instrumento de pesquisa e fonte destes historiadores são obras que só podem ser encontradas porque foram guardadas por filhas, netas, familiares, devido ao seu valor sentimental e histórico para as famílias, e desde então, tais fontes e materiais são analisados também pela psicanalise, antropologia e literatura, consolidando a interdisciplinaridade entre ambas estas áreas relacionadas ao feminino na história ${ }^{3}$.

Contudo temos de ter em mente o que Talita Michelle escreve em sua tese de Mestrado ${ }^{4}$ acerca da escritora Maria de Paula Fleury de Godoi, membro da AFLAG. "Não temos a prepotência de pensar a literatura como o retrato fiel do passado, entendemos que a partir da literatura navegamos em outras ondas, que incluem sentimentos de medo, raiva, ciúmes, paixão, como pode ser percebido nas obras da escritora colocada em discussão". (SOUZA, pág. 66), as mulheres desta forma, são mais imaginadas do que descritas ou contadas, seguidas de estereótipos, e fazer história é, como nos afirma Perrot, antes de tudo, chocar-se contra este bloco de representações, propor críticas e contextualizar mentalidades.

As mulheres adentram os espaços públicos, transformando o saber e inevitavelmente trazem novas questões, como a sexualidade. Margareth

${ }^{3}$ PEDRO, Joana Maria. Relações de gênero como categoria transversal na historiografia contemporânea.

${ }^{4}$ SOUZA, Talita Michelle. A HISTÓRIA DE

MULHERES ESCRITORAS EM GOIÁS:

ATRAVESSANDO

TRAJETÓRIAS E PRODUÇÕES LITERÁRIAS.

Goiânia- GO, 2017. 
Rago, Eleni Varikas ${ }^{5}$ e outras historiadoras de gênero se questionam diante de uma espécie de "amnésia" que permeia determinados grupos sociais, que fez e continua fazendo com que as mulheres sejam marginalizadas, e permanecendo em constante reconfiguração da sua imagem, diante de uma construção cheia de subjetividades, subordinadas aos conceitos existentes na sociedade, naturalizados e universalizados, como, a fragilidade, e inocência, a falta de tato político, etc. Joan Scott atribuiu como "relações de poder" ${ }^{6}$, o que é restringido à mulher como um ambiente privado, alheio às concepções políticas do âmbito público, e desta forma, constata-se que a diferença é produzida através de processos discursivos e culturais, ou seja, a diferença em nossa sociedade presente nos discursos é ensinada. .

A literatura esteve na vida destas mulheres devido ao âmbito cultural da qual são reflexo, pois, a escrita é essencial, Michelle Perrot nos trás uma reflexão importante, ela afirma que depende do grau de alfabetização que lhes foi concedido. Estas mulheres foram agraciadas com uma boa formação, sabiam escrever e ler, e usaram estas habilidades para intervir na sociedade ao seu redor, nascidas de famílias influentes, vivenciavam a política, acompanhando de perto as mudanças sociais e as necessidades culturais. Muitas recorreram aos diários, que se tornam poesias, e posteriormente, após concretizarem-se como confreiras da (AFLAG) na década de 1970, passam a representar o olhar feminino, em

\footnotetext{
${ }^{5}$ Professora em Paris, coordenadora dos estudos de gênero.

${ }^{6}$ Entrevista cedida à ANPOCS.

${ }^{7}$ LOURO, Guacira Lopes. Gênero e sexualidade: pedagogias contemporâneas.
}

colunas de diversos Jornais oficiais como $O$ Popular, e o Diário da Manhã, e publicam inúmeros livros, dos quais observamos discussões sobre a família, o cotidiano, a repressão artística que sofriam, e a falta de incentivo à produção cultural em Goiás. Já havido, contudo, participações femininas em tempos remotos, datados da década de 1930, em alguns Jornais, fundados, por elas mesmas.

Desta forma, a Academia Feminina de Letras e Artes de Goiás (AFLAG) revela suas mulheres/patronas, expondo seu conhecimento nestas publicações, além de dar visibilidade à experiência social, política, lírica, popular e sexual, não só do Estado de Goiás. Michelle Perrot compreendeu isto como um modo de interrogação próprio do olhar feminino, em um ponto de vista especifico das mulheres ao abordar o passado, estas mulheres não estão escrevendo apenas a sua história, mas estão sendo as protagonistas desta escrita, de acordo com a historiadora:

"[...] As mulheres trazem uma experiência histórica e cultural diferenciada da masculina, ao menos até o presente, uma experiência que várias já classificaram como das margens, da construção miúda, da gestão dos detalhes, que se expressa na busca de uma nova linguagem, ou na produção de um contra discurso, é inegável que uma profunda mutação vem-se processando também na produção do conhecimento científico”. (PERROT, In. RAGO, Margareth, p, 03).

A presente pesquisa realizada pretende fornecer uma ampla documentação sobre as 
produções gerenciadas pela (AFLAG), durante seus 45 anos de existência. Foram utilizadas como fontes de pesquisa, suas obras literárias assim como os anuários publicados de 1970 a 20122013, estes que relatam anos consecutivos de atuação destas mulheres, sendo o destaque dentre as fontes, assim como as produções do acervo privado da instituição. As mulheres estão a todo o momento se emancipando em seus campos de atuação, sendo a Política, a educação, a escrita. A visão de uma mulher passiva, incapaz, e fora do âmbito intelectual na história será rompida diante das novas abordagens, e do uso de fontes literárias, neste caso em específico, as mulheres incorporam a dimensão de seu sujeito histórico, compreendem suas limitações e as questionam, construindo uma carga e ótica emotiva, intuitiva, lírica, elas debatem o conhecimento, questionam o corpo, a mente, seus sentimentos, o contexto social que estão inseridas, o amor e a vida.

\section{MATERIAIS E MÉTODOS}

O questionamento das fontes foi realizado de forma sistemática, diante das notícias sobre mulheres que atuaram durante os 45 anos de fundação da Academia, presentes em anuários que, publicados, relatam as atividades da instituição, de modo que, permite-se um aparato geral e retrospectivo da atuação feminina nas artes e literatura, de 1970 - $1^{\circ}$ Anuário, no qual estão as 40 Patronas- até o ano de 2012, sendo que, alguns anuários envolvem dois anos de atuação, e, conforme a Academia se desenvolve e ganha repercussão, acrescentam-se as titulares e correspondentes. Algumas Patronas e titulares, especificamente, para fator de preenchimento, têm como nacionalidade outras regiões, filiandose durantes esses 45 anos. São ao todo 74 (Setenta e Quatro) Mulheres, dentre às quais, almeja-se catalogar seus feitos e obras, assim como, participação cultural e política.

Fez-se um arrolar de dados da presidência da Academia e suas confreiras, durante os anos, em geral, e, posteriormente, atentou-se para cada Anuário/Revista, que originou uma ficha própria, estas fichas por questão de tamanho não foram anexadas neste trabalho, mas aqui foram selecionadas algumas mulheres para cunho de sua importância e justificativa do tema. Verifica-se um resumo da ata de fundação, o número de patronas e (no caso de haver falecimentos) as titulares, e, posteriormente, as biografias das filiadas do respectivo ano, contendo, data de nascimento/óbito, ocupação, temáticas das obras, obras publicadas em vida e obras póstumas, por fim, os prêmios (se for o caso). Dessa maneira, pretendeu-se mapear quais os nomes mais relevantes citados em jornais e revistas que circulavam no Estado e que tipo de atuação política essas mulheres exerceram, além de suas trajetórias, dando respaldo à suas origens.

\section{RESULTADOS E DISCUSSÕES Rosarita Fleury: trajetória de vida e}

\section{produções.}

A idealizadora e fundadora da Academia Feminina de Letras e Artes de Goiás (AFLAG), Maria do Rosário Fleury, nasceu no dia 27 de Outubro de 1913, na Cidade de Goiás, filha de Heitor Moraes Fleury e Josefina Caiado Fleury. No dia de seu nascimento, de acordo com sua filha, Maria Elizabeth Teixeira, "Em oração a 
virgem do Rosário pela graça do feliz parto e o nascimento de uma criança, sadia, pede-lhe o casal, a proteção para a vida de sua filha, dandolhe o mesmo nome, assim se faz a graça de Maria do Rosário Fleury”. (TEIXEIRA, p, 26).

Era uma vez uma menina morena,

Que se chamava Rosarita Fleury.

Na velha cidade de Goiás morava

$e$ a todos encantava

pela suave simplicidade

e pela vibrante inteligência,

que tinha os fulgores do sol batendo, nascendo e se escondendo na lendária Serra Dourada, que põe reflexos de luz na cidade secular e que, mais tarde, projetou, com brilho,

o nome de nosso Estado,

tão digno e tão amado, no cenário literário nacional!

\section{NELLY ALVES DE ALMEIDA}

Uma mulher a frente de seu tempo, manteve sua escrita cuja temática abordava os arredores da Cidade de Goiás, que significava para ela um refúgio. Ao mudar-se para Goiânia quando completou 23 anos, sendo recém-inaugurada em 1933 por Pedro Ludovico Teixeira', Rosarita escreveu "[...] acompanhando a topografia da nova cidade, enquanto na bela Goiás cercada de morros, os pensamentos, ideias e ideais se fechavam em concha, nos descampados que aqui se abria, uma constante mutação de pensamentos

\footnotetext{
${ }^{8}$ Trecho do poema com que Nelly Alves de Almeida (1916/1999) onde se manifestou sobre o livro premiado pela Academia Brasileira de Letras, de Rosarita Fleury, "Elos da Mesma Corrente", em 1958, publicado na Revista de Educação do Estado de Goiás.

${ }^{9}$ Interventor de Goiânia no período, nomeado por Getúlio Vargas.
}

favoreciam e incitava a descoberta de novos valores", demonstrando sua melancolia e saudosismo. Sua Filha Maria Elizabeth ${ }^{10}$ nos relata que a mudança para nova capital abalou toda a sociedade vilaboense ao mexer com os interesses econômicos, políticos, sociais e até com a fraternal amizade havida entre as famílias.

Este é um trecho do poema Goiannia, de Rosarita:

Pois olha, viajante amigo, épara você mesmo que hoje quero falar: É justamente, para você, que aqui do meu sertão, da cidade mais linda e mais faceira de quantas povoaram as terras do oeste brasileiro, vou cantar meu poema-canção Começou, então, sem sonhos nem ilusões, nosso dia a dia em Goiania, capital do Estado”

Desde muito nova, Rosarita, aos 24 anos teve seu primeiro poema, "Retalhos", escrito em 1936 e publicado no Correio da Manhã, em 07 de Março de 1937, eis um trecho:

$$
\text { Ob! Sim... }
$$

Eu tenho saudade...

Daquele quarto singelo

Que sentiu desabrochar

Meu sonho de mocidade

Onde eu dormia a cantar

E de onde... Ao romper do dia,

O sino do campanário

Da Igreja do Rosário

Me acordava pra rezar!...

\footnotetext{
${ }^{10}$ Atual presidente da ALFAG, empossada em 2013.
} 
Haverá a transferência das demais repartições publicas para a Nova Capital, logo, personalidades femininas que estarão presentes no âmbito publico e político, começam a vir para Goiânia, algumas destas são Maria Felix de Souza, Amélia Jardim, Virgínia, Eurydice Natal e Silva, Célia Coutinho Seixas de Brito, das quais muitas comporiam, à posteriori, na década de 1970, alguns dos nomes das cadeiras da AFLAG. Rosarita propõem ainda muito jovem a consolidação de um Jornal intitulado "Que me Importa?", este material irá conter, a sua importância, pelo fato de terem sido publicados "sonhos transformados em letras", e que passavam de mão em mão, até ficar nas palavras de Rosarita, em depoimento, "todo esfacelado".

Neste momento, um grupo de homens e mulheres forma o que será conhecido como Bando da Alegria, todos são amigos e conhecidos de Rosarita, do qual muito valorizava já que era por meio de onde organizavam suas publicações e ganhavam relevância no espaço cultural e deste grupo que surgiram muitos nomes da literatura feminina. Em abril de 1937 houve a solenidade da bênção ao pequeno prédio em que se instalou a Santa Casa da Misericórdia em Goiânia, fundada por Gercina Borges. Foi solicitado que o "Bando da alegria" participasse sendo constante o interesse de Rosarita, aonde se organiza uma quermesse e eventos culturais para arrecadar fundos para conclusão das obras do local e efetivação das primeiras irmãs na direção da casa.

Em 1936 este grupo atuante funda a primeira biblioteca de Goiânia, pensada e organizada com participação de Rosarita Fleury, que em suas palavras afirma:

Éramos cinco a sonhar com isto. Maria das Graças Fleury, Virgínia e Tuniche Viera, Maria Felix de Sousa (Dolly) e eu. Para tanto, organizamos o "Baile do Livro", cujo ingresso para os senhores era um livro. Lembro-me de Haver escrito e enviado o convite a muitos amigos e conhecidos, explicando nossos planos e pedindo um livro. (ROSARITA FLEURY. In. TEIXEIRA, p, 185).

Foram arrecadados 78 volumes e uma estante, e esta ideia originou a atual Biblioteca Municipal de Goiânia. Rosarita Fleury sempre atuou na vida pública de seu tempo. Escrevia sobre a natureza e a formação dos centros de comércio, conversava com suas companheiras e demonstrava vontade de fazer algo a respeito do desenvolvimento da Capital e de seus espaços culturais. Devido a esta ânsia, Rosarita começou a escrever, e junto ao seu crescimento intelectual a ala cultural de Goiânia acabou por expandir-se para novos talentos, a exemplo a Academia Goiana de Letras, que é fundada em 1939, promovendo diversos concursos literários, dentro dos quais Rosarita Fleury fora premiada em 1942, pelo poema "São João" juntamente com o poema "Tocaia” de Bernardo Élis.

Rosarita tem de conciliar sua atuação cultural e como escritora entre a vida privada doméstica familiar, casou-se com o então Engenheiro de Obras do Ministério de Viação Pública, Jerônimo Fleury Teixeira, iniciando a sua vida como esposa e mãe de sua primeira filha em 1944, Maria Elizabeth Fleury Teixeira. No final do 
ano de 1952 a autora terminara seu livro intitulado “Elos da Mesma Corrente”. Após o fim da Segunda Guerra Mundial e as desavenças governamentais e dificuldades ferroviárias em Goiânia, após um tempo, Rosarita Fleury retoma seus trabalhos em 1955, como secretária no Instituto de Educação de Goiás, neste momento conheceu muitas de suas colegas, como a professora Nelly Alves de Almeida e Ana Braga Contijo ${ }^{11}$.

A Narrativa desta obra "Elos da Mesma Corrente", se passa no século XIX, na qual por meio de suas personagens, Rosarita consegue dar luz aos acontecimentos da Guerra, trabalhando com o cotidiano da Cidade de Goiás, destaque para as personagens femininas, nas quais percebo que são reflexos do que Rosarita vivenciou, assim como as demais mulheres de seu tempo. Neste livro a autora expõem suas opiniões, a exemplo os medos e temores em relação ao casamento, e como são doutrinadas a reprimir suas vontades, em tornarem-se mães muito cedo, e donas de casa, cuja valorização da honra e das virtudes da época estava na figura da mãe e esposa felizes ${ }^{12}$.

O livro foi publicado em 1958, e recebe o prêmio Júlia Lopes de Almeida, em 1959 da Academia Brasileira de Letras. Apenas o reconhecimento desta obra já visava para Rosarita Fleury o titulo de primeira mulher romancista em Goiânia, em que insere Goiás no meio literário brasileiro. Observa esta relevância, além da produção das mulheres na sociedade goiana que

\footnotetext{
${ }^{11}$ Colegas de trabalho, que junto a Rosarita idealizam a Academia Feminina de Letras e Artes de Goiás-AFLAG, em 1969.

12 Ver: SOARES, Ana Carolina Eiras Coelho. Moça Educada, Mulher Civilizada, Esposa Feliz: Relações de gênero e história em José de Alencar. Rio de Janeiro: Dissertação de mestrado, PPGH - UERJ, 2003. Mimeo.
}

começa a ter ênfase após Rosarita ganhar este destaque, revela um campo fértil, de grandes artistas, não só na literatura, mas também nas artes em geral.

Rosarita Fleury não foi aceita na Academia Brasileira de Letras. Devido a questões políticas da época, esta não aceitava mulheres, pois seguia com o modelo Francês. A profunda frustração com essa conjuntura, a após ter um número grande de mulheres que almejavam publicações, Rosarita Fleury idealiza ao lado de Nelly Alves de Almeida e Ana Braga Gontijo, a Academia Feminina de Letras e Artes de Goiás (AFLAG). A Academia acabou por se tornar um manifesto contra a segregação das mulheres no âmbito da escrita e intelectualidade. Durante os anos de sua consolidação, a Academia promoveu uma árdua seleção de nomes para o seu preenchimento de 40 cadeiras, ao modelo da Academia Brasileira de Letras, só que com um grande diferencial: seriam todas mulheres.

Rosarita acaba por ser aceita a ocupar a Cadeira n³1 da AGL-Academia Goiana de Letras, na qual anteriormente ocupava Eurydice Natal e Silva, outro nome de grande destaque. Seu ultimo ano de vida foi acompanhada de muita atuação pública, em constantes encontros promovidos pela Academia, e debates sobre a importância e preservação de sua existência. 14 de Março do ano de 1993 vêm a falecer, aos oitenta anos, após ter presidido a AFLAG por 23 anos consecutivos.

Rosa rocha ita. Rocha pedra pluma. 
Pluma pedra, mulher. ${ }^{13}$.

(AFLAG) Academia feminina de letras e artes de Goiás: conhecendo as escritoras e artistas.

A AFLAG foi fundada em 1969. Segundo relatos de Maria Elizabeth Teixeira, no livro que escreveu em homenagem à sua mãe, a ideia surgiu de uma reunião informal. Discutia-se a injustiça à inteligência feminina.

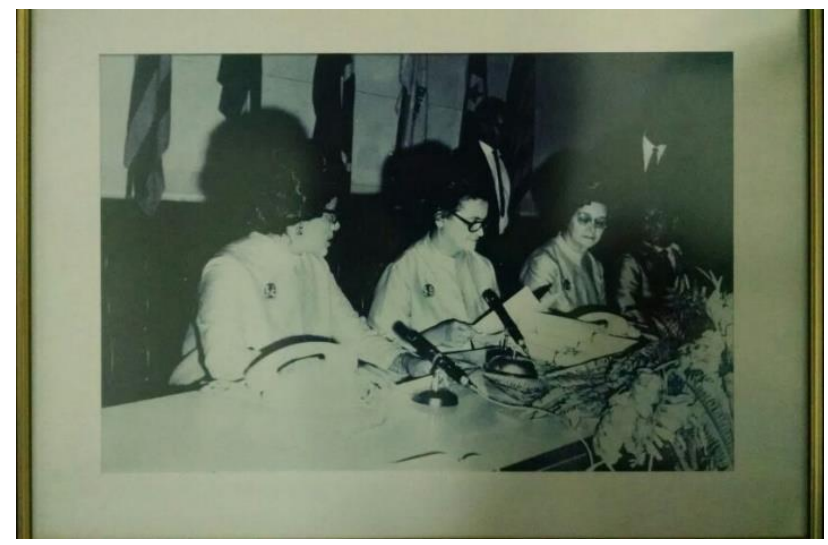

[TFF] Posse no dia 09 de Novembro de 1970, $1^{\circ}$ aniversário da AFLAG na Assembleia Legislativa de Goiânia. À esquerda, Nelly Alves de Almeida, ao centro Rosarita Fleury, à direita ao final, Ana Braga Contijo.

Nos próximos anos, refletia-se muito à cerca do trabalho feminino no território Goiano, abrangendo as artes e a escrita. Rosarita promoveu uma busca árdua para preencher as 40 cadeiras da (AFLAG), e foi verificado que muitas mulheres, ao receberem o convite para filiarem-se na Academia sentiam-se inseguras em se expor à tamanha tarefa de representação. Fez-se um levantamento de suas vidas e obra das literatas, tanto das escritoras como das artistas e educadoras do Estado, esta busca se faz presente

\footnotetext{
${ }^{13}$ Judite Furtado Miranda, sócia-suplementar. Trecho do poema $R O S A(R) I T A$.
}

no Anuário de 1970, composto por 39 confreiras, nomes como Goiandira do Couto, Neusa Rodrigues de Moraes e Cora Coralina estão presentes.

Após as filiações se concretizarem, muitas passaram a publicar livros anualmente, cuja palavra legitima-se e tinha espaço diante da Academia. Segundo Perrot, "as mulheres diante da história deixaram em suas autobiografias o testemunho do que foi para elas difícil o aprendizado da palavra pública, mas também o prazer que elas sentiam ao fazê-lo". (PERROT, 2005). Dentro os relatórios de atividades do ano de 1969, a (AFLAG) prestou sua homenagem à Eurydice Natal e Silva ${ }^{14}$, que mesmo com saúde debilitada, compareceu a fundação, vindo a falecer no ano seguinte, em 1970, antes, tomando posse da cadeira $n^{\circ} 11$

O anuário de 1970 foi lançado no Segundo aniversário da Entidade, em comemoração festiva no dia 27 de novembro de 1971. Sobre a ata de fundação, o primeiro anuário trará, não apenas a apresentação da Academia, como também todo o seu estatuto, e com ele, de 1969, por diante, fazendo-se na integridade do cumprimento dos requisitos essenciais, e todas as confreiras, agora presentes como patronas de suas cadeiras, devem zelar pela cultura e pelo campo artístico social, servindo de estimulo às demais gerações. Eis um panorama da ata de fundação:

No dia 09 de Novembro de 1969, na Capital Goiânia do Estado de Goiás, na casa de n¹23 da Avenida Tocantins, deu-se inicio, às

\footnotetext{
${ }^{14}$ Fundou a Academia de letras, em Goiás, no ano de 1904.
} 
20 horas, à solenidade da fundação. Presidindo a reunião, Rosarita Fleury, Nelly Alves de Almeida e Ana Braga Contijo. Em discursos, ressaltaram que os propósitos e finalidades da Academia a ser fundada, é ser o ideal de todas, convidando para ocupar as cadeiras, as pioneiras da literatura goiana. A seguir, expos Ana Braga, a dificuldade que passam os goianos do Norte, onde faltavam escolas. Rosarita, completou, defendendo a iniciativa da literatura e da cultura, levando Goiás para o mapa, para que seja respeitado como Estado das artes femininas, por fim, lembrou-lhes de seu livro "Elos da Mesma Corrente", de 1958, da qual ganhou o prêmio Julia Lopes de Almeida, pela Academia brasileira de Letras, em 1959.

(ANUÁRIO, 1970).

É um todo de 74 (setenta e quatro) mulheres. Sendo destas 40 Mulheres presentes na fundação, compondo as cadeiras escolhidas. Por questão de espaço não conseguiremos abordar todas, porém trouxemos alguns exemplos artísticos e de atuação política.

No ato de publicação da Fundação, foi-se concretizado um catalogo próprio, de 1970, denominado "As 40 Imortais", para fator de publicação em Jornal, apenas na época. A Academia foi duramente criticada, a princípio foram delegados adjetivos como, "uma rebelião de saias", ou "clube de Luluzinha", contudo, isto não abalou os alicerces da publicação, cujo objetivo, nas palavras de Nelly Alves de Almeida, era de propor a conscientização das artes femininas.
Foram encontradas participações no âmbito social e cultural, na Cidade Goiás, da já falecida, Eurídice Natal e Silva, patrona da cadeira $n^{\circ} 11$, empossada em 1970 , presente no primeiro Anuário, fundadora da Academia de Letras, sediada na respectiva cidade, antes capital, em 1904, encontrando-se de forma atuante, até 1908. Observou-se sua conscientização diante da problemática da atuação feminina na escrita, expondo princípios de uma escrita feminista.

Sobre os destaques da fundação, encontrase Ana Braga Gontijo, ocupando a cadeira no 04 da (AFLAG) Academia Feminina de Letras e Artes de Goiás, como uma das fundadoras, em 1969. De origem humilde, nasceu em 29 de novembro de 1923 (Peixe-GO, atualmente Tocantins). Iniciou seus estudos em sua cidade natal, sendo alfabetizada pelo seu avô, Joaquim Nunes Pinheiro. Prosseguiu na cidade goiana de Porangatu e em 1935, estudou em Trindade, ano seguinte, no tradicional Colégio Santa Clara, em Goiânia, bacharelando-se normalista. Em 1941, é nomeada pelo Interventor Federal de Goiás, Pedro Ludovico Teixeira, professora da Escola isolada da Cidade de Paraúna. "Possuidora na pele a cor do bronze sonoro das capelinhas perdidas do norte goiano.” (AFLAG, Anuário, 1970).

Em 1947, é eleita vereadora na primeira legislatura municipal de Goiânia, logo em seguida, ingressa na Faculdade de Filosofia da Universidade Católica de Goiás. Professora no Lyceu de Goiânia, Colégio Santa Clara, Instituto de Educação de Goiás e em 1957, é nomeada diretora do Ensino do Primeiro Grau, da Secretaria da Educação e Cultura do Estado. Aposenta-se, como procuradora do Estado de 
Goiás, representando o Tocantins. Da mesma forma, Nelly Alves de Almeida, ocupante da cadeira no 31, nascida em 01 de outubro de 1916 (Jaraguá-GO), falecida em, 05 de dezembro de 1999, que se juntou às escritoras Ana Braga e Rosarita Fleury, e fundaram a Academia Feminina de Letras e Artes de Goiás. Fez parte da União Brasileira de Escritores de Goiás, do Instituto Histórico e Geográfico de Goiás e pertenceu ao Conselho Estadual de Cultura Municipal de Goiânia sendo sócia-correspondente da Academia Brasileira de Filologia.

Posteriormente, em 1950, Almerinda Magalhães Arantes, ocupante da cadeira $n^{\circ} 03$. Nasceu em 03 de Janeiro de 1906, Posse-Goiás, vindo a falecer em 02 de Julho de 1996. Elegeu-se deputada Estadual, pelo partido do (PTB), em um momento em que as mulheres eram reservadas apenas às tarefas domésticas, sendo a segunda mulher goiana, eleita deputada Estadual, entre 1955 até 1967 . Uma mulher que buscava sempre ampliar seus horizontes, e servir a todas as comunidades a que pertenceu, no âmbito social. Como fato relevante, Foi à primeira mulher goiana a requerer o seu título de eleitor, o que foi deferido, pelo então Juiz de Direito, Dr. Moacir José de Morais, quando houve eleição para Prefeitura de Formosa, interior goiano, com 21 anos de idade. (Entretanto seu voto não foi aceito pelo Presidente da Junta eleitoral, afinal, o título de uma mulher não tinha valor moral). Por meio destes relatos, fica evidente a participação da mulher goiana no meio público e político.

$\mathrm{Na}$ música, como destaque, Maria das Dores Ferreira Aquino (Cadeira $\left.n^{\circ} 20\right)$, nasceu em 25 de Setembro de 1932. Silvânia, Goiás, faleceu em, 05 de Abril de 1990. Foi aluna de Villa Lobos, entre outros, $1^{\circ}$ pianista da Orquestra Sinfônica de Goiás. Em 1956, com 24 anos, foi uma das fundadoras do Conservatório de Musica, hoje (2007), Escola de Música e Artes Cênicas da Universidade Federal de Goiás, onde também foi Professora, ao lado de Belkiss Spencière. Junto a esta, Heloísa Barra Jardim, cadeira n ${ }^{\circ} 17$, nascida em 08 de Julho de 1937. Uberaba- Minas Gerais. Foi Vice-presidente da ordem dos músicos do Brasil. Participou como pianista oficial, de diversos concursos nacionais de piano (Goiânia).

No âmbito do teatro e da cultura, encontrase Floracy Pinheiro, ocupante da cadeira $n^{\circ} 12$. Nasceu em 05 de Junho de 1929. Campoformoso, Goiás, falecendo em 09 de novembro de 2002. Goiânia-GO. Pioneira nas atividades artísticas em Goiás foi a primeira a trazer de fora um profissional para atuar em Goiás, diretor J. Ângelo La banca. Fundou a Cia profissional Cici Pinheiro de teatro em Goiás, e trouxe o cinema popular, pelo filme "Ermitão de Muquém" do Clássico romance de Bernardo Guimarães. Trabalhou na TV Tupy, na rádio Nacional, rádio Cultura e na TV Paulista em, 1952. Autora dos primeiros beijos em palco teatral ao vivo, com o ator William Aia na peça Deslumbramento de São Paulo. "No outro dia eu não tive mais acesso a nenhum lar em Goiânia. Fui taxada de prostituta. Eu não tinha mais ambiente", menciona Cici, em uma entrevista ao jornal que foi publicado em memoria de sua morte, datado de 2005. (O popular, 05 de Junho de 2005). Rompe desta maneira, com os padrões femininos de sua época, revelando-se uma mulher forte e ousada, uma mulher misteriosa e polêmica, soube nutrir o seu 
povo com o que de melhor havia nas artes cênicas e contribuir para um teatro público e educativo que abrange, inclusive, o publico infantil. Cici foi levada ao (DOPS) Departamento de ordem política e social, no período da ditadura, na década de 1960, para "explicar" o porquê daqueles beijos e suas insinuações.

Por fim, temos, a exemplo, escritoras e poetisas, como Graciema Machado, que nasceu em 12 de Dezembro de 1906. Jaraguá-GO. Vindo a falecer em 12 de Julho de 1985. Seus trabalhos já recebiam críticas nos idos do século XX, participando mesmo que minimamente da vida cultural da época, assim como suas companheiras e colegas Maria Paula Godoy, Leogedária de Jesus e Genezy de Castro e Silva. Vista por todos como moça "romântica e sonhadora", escrevia sobre o feminismo e sobre a necessidade do voto já em 1920, publicando o livro Um Novo estilo, O feminismo em Goyár, 1926, evidenciando sua consciência à cerca de política ao seu redor.

\section{CONCLUSÕES}

De fato, Rosarita Fleury representa simbolicamente uma iniciativa, na qual envolvemo-nos em todos os aspectos dos estudos de gênero, e não somente a ela coube este papel. Rosarita foi aceita, só então, em 1977, na Academia Goiana de Letras, ocupando a cadeira n³1, anteriormente, de Eurídice Natal e Silva, isso após fundar a sua Academia, (AFLAG), como respaldo à conscientização feminina. A voz feminina é desconsiderada no ambiente Público, quando são exaltadas, incomodam, e são consideradas tagarelices sem sentido algum, desta forma, Segundo Perrot, restaurar a "ordem" é impor o silêncio às mulheres concomitantemente. Aos poucos a inserção feminina no campo da intelectualidade resgata a confiança das mulheres, diante de um ambiente predominantemente masculino. Nas palavras de Rosarita, e das demais confreiras, a (AFLAG) significa mais do que um espaço de conferências culturais, mas também, um refúgio para as demais gerações de escritoras, que almejam produzir e contribuir para o conhecimento. O grupo de mulheres acadêmicas deveria espelhar honradez no trabalho, dentro e fora do lar, em sua vida artística, cultural, social e educacional, este era o pensamento norteador das fundadoras. O ponto de vista feminino, muitas vezes, trás perspectivas diferenciadas do masculino, como afirma Margareth Rago, de modo a produzir um contra discurso, na construção miúda de uma nova linguagem, promovendo profunda mutação para produção do conhecimento científico. (RAGO, 1998. p, 03).

A escolha deste recorte temporal emergiu da necessidade a respeito da invisibilidade histórica das mulheres, ou seja, submetidas, desvalorizadas e relegadas ao esquecimento. A experiência das acadêmicas contribui consideravelmente para os estudos de gênero, ao compreendermos suas aspirações, como construções históricas da luta feminina, pela emancipação política e intelectual. Tomar este ponto de vista é fecundo, proporciona interrogações sobre as práticas e as relações de poder e mentalidades. "O distanciamento, proporcionado entre o público e o privado, aumenta o sentimento de estranheza em 
detrimento ao feminino". (PERROT, 2005, p. 267).

Os estudos de gênero começam a ganhar força a partir de 1970. Segundo Rago, é ao longe de 1980, porém, que emerge o que se poderia considerar uma segunda vertente das produções acadêmicas sobre as mulheres. (RAGO, 1998. p, 82). Elaboram-se inúmeras discussões, dentre estas, me pergunto, qual o grau de atuação destas mulheres? Como contextualizar seus silêncios? Qual a importância de estudar tais biografias? De fato, confere-se ao sujeito particular aqui descoberto, e, portanto, sua capacidade de luta e participação nas transformações sociais. Certamente, exponho não uma história das mulheres, mas uma história escrita por mulheres, em diários, correspondências, livros de poesia e prosa romântica, parafraseando seus sentimentos e angústias, observações políticas e sociais, construídas na literatura que produzem.

É essa luta política que eu penso que deve comandar a nossa atenção, porque gênero é a lente de percepção através do qual nós ensinamos o significado de macho/fêmea, masculino/feminino. Uma "Análise de gênero" constitui nosso compromisso crítico com esses significados, e nossa tentativa de revelar suas contribuições $\mathrm{e}$ instabilidades, como se manifestam nas vidas daqueles que estudamos. (SCOTT, 2012).

\section{REFERÊNCIAS BIBLIOGRÁFICAS}

BLOCH, Marc. Apologia da História, ou, Oficio do Historiador. Trad: André Telles, _Rio de Janeiro. Ed. Jorge Zahar, 2001.
BOURDIEU, Pierre. O poder do Simbólico. Rio de Janeiro: Bertand Brasil, 2001.

BANDINTER, Elisabeth. Um Amor Conquistado. $O$ mito do amor materno. Rio de Janeiro: Nova Fronteira, 1985.

CHARTIER, Roger. História Hoje: dúvidas, desafios, propostas. In. Estudos Históricos, Rio de Janeiro, vol 07, $\mathrm{n}^{\circ} 13,1994, \mathrm{p} 97-$ 113.

DEL PRIORI, Mary. Ao sul do corpo: condição feminina, maternidades e mentalidade no Brasil Colônia. Brasília. Ed: UnB. José Olimpo, 1993.

PEDRO, Joana Maria. Traduzindo o debate: o uso da categoria gênero na pesquisa histórica. História, São Paulo, v.24, N. 1, p. 77-98, 2005.

FLEURY, Rosarita. Elos da mesma corrente. Ed. Mundial. 2011.

LE GOFF, Jacques, 1924. História e Memória. Tradução: Bernardo Leitão... [et al.] -Campinas, SP Editora da UNICAMP, 1990.

LOURO, Guacira Lopes. Gênero e sexualidade: pedagogias contemporâneas. UFRGS. Ed: Proposições, V.19, n 2(56)- maio/ago. 2008;

PERROT, Michelle. As Mulheres ou os Silêncios da História. Bauru. SP, Ed. EDUCS. 2005.

PERROT, Michelle. Uma história das mulheres é realmente possivel? Paris: Rivage, 1984.

RAGO, Margareth. As mulheres na historiografia brasileira. SILVA, Zélia Lopes (org.). Cultura História em debate. São Paulo: UNESP, 1995, p. 81-98.

\section{Epistemologia Feminista, Gênero e}

História. Florianópolis: Ed. Mulheres, 1998.

SOUZA, Talita Michelle. A História das Mulheres Escritora em Goiás: Atravessando trajetórias e Produções literárias. UFG. Goiânia- GO, 2017. Domínio Público. 
SOARES, Ana Carolina Eiras Coelho. Moça

Educada, Mulher Civilizada, Esposa Feliz: Relações de gênero e história em José de Alencar. Rio de Janeiro: Dissertação de mestrado, PPGH - UERJ, 2003. Mimeo

TEIXEIRA, Maria Elizabeth. Rosarita Fleury, Minha Mãe. Ed: Kelps. 2014.

\section{Fontes}

Anuário de 1970, 1971-72 e de 1973. Revista, (AFLAG). 2013.

Estatuto redigido em 09 de Novembro de 1969 (Anuário-AFLAG, 1970).

Estatuto redigido em 14 de Fevereiro de 2013

VASCONCELLOS, Eliane. Percursoras da (Revista-AFLAG, 2013). literatura Goiana. In. Revista UFG/ Julho/ Ano XII no 08 . 